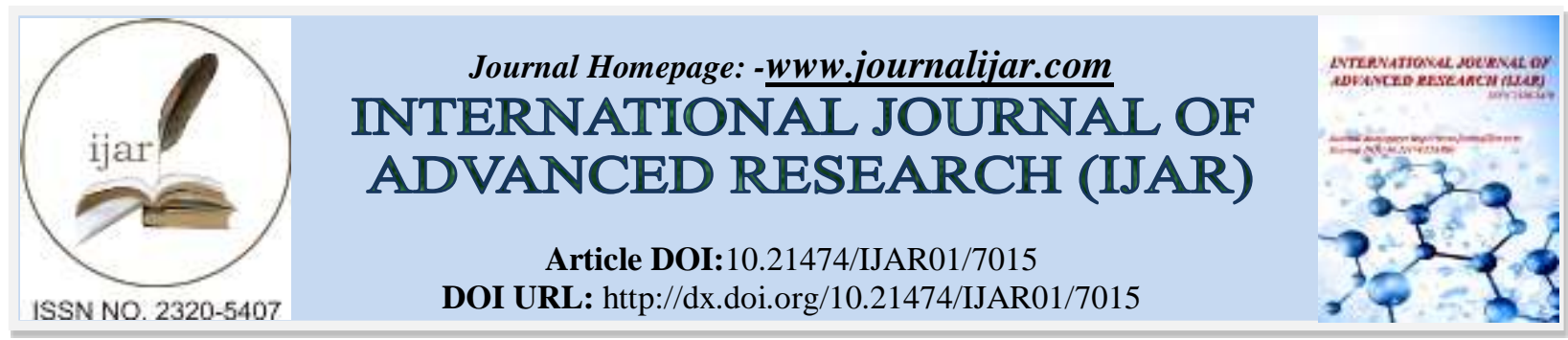

RESEARCH ARTICLE

\title{
ION-SELECTIVE MEMBRANE SENSORS FOR DETERMINATION OF BRIMONIDINE TARTRATE IN BULK POWDER, PHARMACEUTICAL EYEDROPS AND BIOLOGICAL FLUIDS.
}

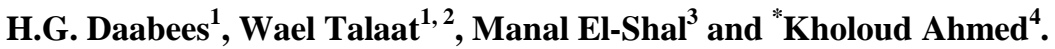 \\ 1. Faculty of Pharmacy, Damnhour University, Damnhour, Egypt. \\ 2. Department of nanoengineering, University California San Diego (UCSD), La Jolla, CA 92093-0448. USA \\ 3. National organization for drug control and research, (NODCAR), Cairo, Egypt. \\ 4. Faculty of Pharmacy, Fayoum University, Fayoum, Egypt.
}

\section{Manuscript Info}

Manuscript History

Received: 02 March 2018

Final Accepted: 04 April 2018

Published: May 2018

Keywords:-

Brimonidine Tartrate; Phosphotungestic

Acid, Phosphomolybdic Acid,

Tetraphenyl Borate, Electrode.

\begin{abstract}
Three novel brimonidine tartrate (BRD) selective electrodes were investigated with di-octyl phthalate as a plasticizer in a polymeric matrix of polyvinyl chloride (PVC). Sensor 1 was fabricated using phosphotungestic acid (BRD-PTA), while sensor 2 was constructed using phosphomolybdic acid (BRD-PMA), whereas sensor 3 was constructed using sodium tetraphenyl borate (BRD-TPB) as ionophores. Linear responses of $\mathrm{BRD}$ within the concentration ranges of $10^{-7}$ to $10^{-2} \mathrm{~mol} / \mathrm{l}$ for sensors 1,2 and 3 were observed. Nernstian slopes of $31.88,29.83$ and $28.50 \mathrm{mv} /$ decade were observed over the $\mathrm{pH}$ range of 3-5 for sensors 1,2 and 3, respectively. The selectivity coefficients of the developed sensors indicated excellent selectivity for BRD. The proposed sensors displayed useful analytical characteristics for the determination of BRD in bulk powder, pharmaceutical formulation and biological fluids (plasma and urine). The novel electrodes offer the advantage of determination of BRD in biological fluids without pretreatment which is convenient for monitoring BRD levels in clinical studies.
\end{abstract}

Copy Right, IJAR, 2018,. All rights reserved.

\section{Introduction:}

Glaucoma is a group of diseases that can damage the eye's optic nerve and result in vision loss and blindness. It is normally associated with increased fluid pressure in the eye (aqueous humor). Ocular hypertension is intraocular pressure higher than normal in the absence of optic nerve damage or visual field loss [1,2]. Brimonidine tartrate (BRD) (fig. 1), [5-bromo-6- (2-imidazolidinylideneamino) quinoxaline 1-tartrate] is alpha-adrenergic agonist drug that reduces secretion of aqueous humor and increases scleral outflow [3].

The literature survey reveals several analytical methods for quantitative estimation of BRD in body fluids and in pharmaceutical formulations by spectrophotometry [4-10], liquid chromatography [11-21] and electrochemical methods [22-24].

The objective of this study is to develop sensors that can be successfully applied for the electrochemical determination of BRD in raw form, pharmaceutical eyedrops and biological fluids without the need of preliminary extraction or cleaning up procedures. 
Figure 1: The structural formula of brimonidine tartrate (BRD)

Brimonidine tartrate:

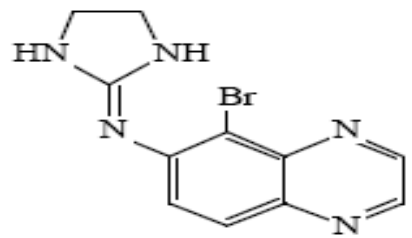<smiles>O=C(O)C(O)C(O)C(=O)O</smiles>

Experimental:

Apparatus:

A Jenway digital ion analyzer model 3330 (Jenway, UK) with $\mathrm{Ag} / \mathrm{AgCl}$ double junction reference electrode no Z113107-1EA (Aldrich, USA) was used for potential measurements. A Jenway pH glass electrode (Jenway, UK) was used for $\mathrm{pH}$ adjustments.

Chemicals and reagents:-

Pharmaceutical pure samples:-

Reference brimonidine tartrate (BRD) was kindly donated by Orchidia Pharmaceuticals CO., Cairo, Egypt.

\section{Pharmaceutical dosage form:-}

Alphanova ${ }^{\circledR}$ eyedrops:-

Eyedrops labeled to contain $1.5 \mathrm{mg}$ of BRD supplied by Orchidia Pharmaceuticals CO., Cairo, Egypt, were purchased from local market.

\section{Reagents:-}

All chemicals and reagents used throughout this work were of analytical grade. Water used was bi-distilled. Hydrochloric acid and sodium hydroxide scales were obtained from Biochem., Cairo, Egypt. Polyvinyl chloride (PVC), phosphomolybdic acid (PMA), tetraphenyl borate (TPB) phosphotungestic acid (PTA), dioctyl phthalate (DOP) and tetrahydrofuran (THF) were obtained from Aldrich, USA. Potassium chloride was obtained from El-Nasr pharmaceutical chemicals, Cairo, Egypt. Starch, lactose, $\mathrm{CaCl}_{2}, \mathrm{NaCl}$, glucose, mannitol and urea were obtained from Adwic, Cairo, Egypt.

\section{Standard solutions:-}

BRD standard stock solution $\left(1 \times 10^{-1} \mathrm{M}\right)$ :

It was freshly prepared daily by transferring $4.422 \mathrm{~g}$ of BRD into $100-\mathrm{ml}$ volumetric flask and dissolving in distilled water and tightly closed.

BRD working solutions $\left(1 \times 10^{-8}-1 \times 10^{-2} \mathrm{M}\right)$ :

They were freshly prepared by suitable dilution from their stock solution using distilled water and kept in wellclosed tight container.

\section{Procedures:}

\section{Precipitation based technique and fabrication of membrane sensors:}

In three different beakers, a volume of $50 \mathrm{ml}$ of BRD tartrate solution was mixed with $50 \mathrm{ml}$ of aqueous $1.0 \times 10^{-2}$ $\mathrm{M}$ aqueous phosphotungestic acid solution (beaker 1), a volume of $50 \mathrm{ml}$ of BRD tartrate solution was mixed with $50 \mathrm{ml}$ of aqueous $1.0 \times 10^{-2} \mathrm{M}$ aqueous phosphomolybdic acid solution (beaker 2) and a volume of $50 \mathrm{ml}$ of BRD tartrate solution was mixed with $50 \mathrm{ml}$ of $1.0 \times 10^{-2} \mathrm{M}$ aqueous solution sodium tetraphenyl borate (beaker 3). The resultant precipitates in (beakers 1, 2 and 3) were filtered using Whatman no.42 paper, washed with cold water, dried at room temperature (about $20^{\circ} \mathrm{c}$ ) and grinded to fine powder. Elemental analysis of the formed complexes was carried out.

In three glass petri dishes $(5 \mathrm{~cm}$ diameter), $10 \mathrm{mg}$ of the three ion exchangers were separately mixed with $0.35 \mathrm{ml}$ of DOP and $190 \mathrm{mg}$ of PVC. The mixtures were dissolved in $5 \mathrm{ml}$ of THF. The petri dishes were covered with filter papers and left to stand overnight to allow solvent evaporation at room temperature. Master membranes with a thickness of $0.1 \mathrm{~mm}$ were obtained. Disks $(\approx 8 \mathrm{~mm}$ diameter) were cut using a cork borer and pasted using THF 
to interchangeable PVC tips that was clipped into the end of the electrode glass body. Equal volumes of $10^{-2} \mathrm{M}$ aqueous drug solution (BRD) and $10^{-2} \mathrm{M} \mathrm{KCL}$ were mixed and the solutions were used as internal reference solutions. $\mathrm{Ag} / \mathrm{AgCl}$ wire $(1 \mathrm{~mm}$ diameter) was immersed in the internal reference solution as an internal reference electrode. The sensors were left for equilibration in $10^{-2} \mathrm{M}$ aqueous drug solution for 24 hours.

Figure 2: Suggested structural formula of ion association complexes of BRD with phosphotungestic acid.

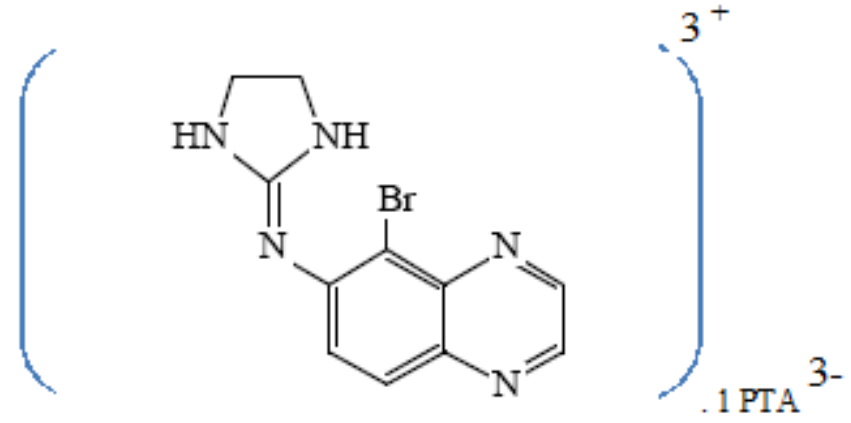

Figure 3: Suggested structural formula of ion association complexes of BRD with phosphomolybdic acid.

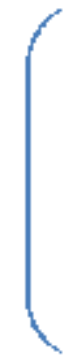<smiles>Brc1c(N=C2NCCN2)ccc2nccnc12</smiles>

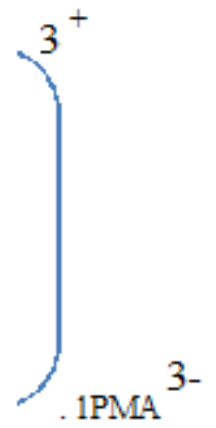

Figure 4: Suggested structural formula of ion association complexes of BRD with tetraphenyl borate

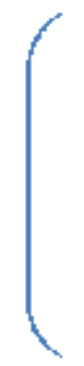<smiles>Brc1c(N=C2NCCN2)ccc2nccnc12</smiles>

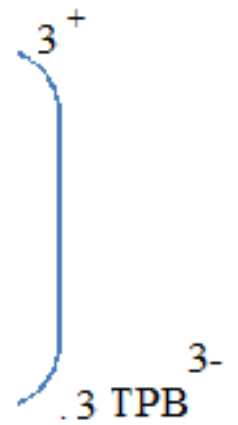

\section{Electrode calibration:}

The prepared electrodes were immersed in conjunction with the double junction $\mathrm{Ag} / \mathrm{AgCl}$ reference electrode in aqueous drug solutions (BRD) in the range of $1 \times 10^{-8}$ to $1 \times 10^{-2} \mathrm{M}$. They were allowed to equilibrate while stirring and recording the e.m.f. readings within $\pm 1 \mathrm{mv}$. The membrane sensors were washed in bi-distilled water between measurements. The e.m.f was recorded as a function of drug concentration then calibration graphs of the recorded potentials vs.- -log drug concentrations were plotted. This calibration plots or the computed regression equations (of the linear part of the curves) were used for subsequent measurements of unknown concentrations of (BRD). 


\section{Study of the experimental conditions:}

Identification of the slope, response time and operative life of the studied electrode:

The electrochemical performance of the proposed sensors was evaluated according to the IUPAC recommendations data. The dynamic response time of the electrodes for the concentrations of $1 \times 10^{-8}-1 \times 10^{-2} \mathrm{M}$ drug solutions was tested. The sequence of measurements was from low to high concentrations. The time required for the electrode to reach the final equilibrium potential was measured.

\section{Effect of pH:}

The effect of $\mathrm{pH}$ on the potential values of the proposed electrodes was studied by immersing the electrodes in $10^{-3}$ $\mathrm{M}$ drug solutions in $\mathrm{pH}$ ranging from 2 to 8 using $0.1 \mathrm{M} \mathrm{NaOH}$ and $0.1 \mathrm{M} \mathrm{HCl}$.

\section{Sensors selectivity:}

The potential response of the proposed electrodes towards different substances was examined. The potentiometric selectivity coefficient, - $\log$ ( $\mathrm{k}$ pot primary ion, interferent) was used to evaluate the extent to which a foreign ion would interfere with the response of the electrode to its primary ion. The selectivity coefficients were calculated using the separate solutions method. The potentials were measured for $10^{-3} \mathrm{M}$ BRD solution and then for $10^{-3} \mathrm{M}$ aqueous interferent solution, separately, then potentiometric selectivity coefficients were calculated using the following equation.

$$
\text { Log pot. K1, } 2=\left[(\mathrm{E} 1-\mathrm{E} 2) /\left(2.303 \mathrm{RT} / \mathrm{Z}_{\mathrm{a}} \mathrm{F}\right)\right]+\left[1-\left(\mathrm{Z}_{\mathrm{a}} / \mathrm{Z}_{\mathrm{b}}\right)\right] \log [\mathrm{A}]
$$

Where $\mathrm{E} 1$ is the potential measured in $10^{-3} \mathrm{M}$ drug solution (BRD), E2 the potential measured in $10^{-3} \mathrm{M}$ interferent solution, $\mathrm{Z}_{\mathrm{a}}$ and $\mathrm{Z}_{\mathrm{b}}$ are the charges of drug and interfering ion, respectively, $\mathrm{A}$ is the activity of drug and $2.303 \mathrm{RT} /$ $\mathrm{Z}_{\mathrm{a}} \mathrm{F}$ represents the slope of the investigated sensor ( $\mathrm{mV} /$ concentration decade).

\section{Application of the proposed method for determination of BRD in Alphanova ${ }^{\circledR}$ eyedrops:} A portion of Alphanova ${ }^{\circledR}$ eyedrops solution equivalent to $1.105 \mathrm{mg}$ BRD was transferred into 25 -ml volumetric flask and filled to the mark with bi-distilled water to prepare $1.0 \times 10^{-4} \mathrm{~mol} \mathrm{~L}^{-1}$ stock solution, then a serial dilution was made from the prepared stock to obtain $1.0 \times 10^{-5}$ and $1.0 \times 10^{-6} \mathrm{~mol} \mathrm{~L}^{-1}$ samples. The potentiometric measurements of the prepared samples were performed using the proposed sensors in conjunction with reference electrode and the concentration of BRD was obtained from the corresponding regression equation.

\section{Determination of BRD in plasma:}

One milliliter of each of $10^{-2}, 10^{-3}$ and $10^{-5} \mathrm{~mol} \mathrm{~L}^{-1}$ standard drug solution was added separately into three $20-\mathrm{ml}$ stoppered shaking tubes each containing $9 \mathrm{ml}$ of plasma and the tubes were shaken for $1 \mathrm{~min}$. The membrane sensors were immersed in conjunction with the reference electrode in these solutions and then washed with water between measurements. The e.m.f. produced for each solution was measured by the proposed sensors, and the concentration of BRD was obtained from the corresponding regression equation.

\section{Determination of BRD in urine:}

One milliliter of each of $10^{-2}, 10^{-3}$ and $10^{-5} \mathrm{~mol} \mathrm{~L}^{-1}$ standard drug solution was added separately into three 20$\mathrm{ml}$ stoppered shaking tubes each containing $9 \mathrm{ml}$ of urine and the tubes were shaken for $1 \mathrm{~min}$. The membrane sensors were immersed in conjunction with the reference electrode in these solutions and then washed with water between measurements. The e.m.f. produced for each solution was measured by the proposed sensors, and the concentration of BRD was obtained from the corresponding regression equation.

\section{Results and discussion:}

The present work evaluated the possibility of quantitative determination of BRD by using selective membrane sensors with ion exchanger PTA, PMA and TPB in its composition using PVC as a polymeric matrix to immobilize the sensors and to attain the formation of highly stable complexes. It was found that the three ionic exchangers have low solubility product and suitable grain size. BRD was found to form 1:1 ion association complex with PTA, PMA and 1:3 ion association complex with TPB. The proposed sensors were used for the determination of BRD in bulk powder, pharmaceutical formulations and biological fluids. 


\section{Performance characteristics of sensors:}

The electrochemical performance characteristics of the investigated sensors were evaluated according to the IUPAC recommendation data [25]. It is summarized in table 1. It has been reported that PVC matrix is a regular support and reproducible trap for ion association complexes in membrane sensors. In the present study, dioctyl phthalate (DOP) has been used in the fabrication of the proposed membrane sensors. It adjusted the permittivity of the final organic membranes and mobility of the ion exchanger sites. The membranes constituents were dissolved in THF that was slowly evaporated at room temperature leading to membrane formation. The three sensors showed best sensitivity, where linearity was obtained in the range of $\left(10^{-2}-10^{-7} \mathrm{M}\right)$. Sensors 1,2 and 3 showed good slope 31.89, 29.83 and $28.50 \mathrm{mV} /$ decade, respectively. Deviation from the ideal Nernstian slope $(60 \mathrm{mV})$ is due to the electrodes responding to the activity of the drug cations rather than its concentration. The potential displayed by the proposed electrodes for constructive measurements of standard drug solution in the same day and from day to day did not vary by more than $\pm 1 \mathrm{mV}$ using the proposed sensors. Calibration slope didn't change by more than $\pm 2 \mathrm{mV}$ per decade concentration. The detection limits of the three sensors were estimated according to the IUPAC definition [25]. The slopes of the calibration plot did not change significantly but show a gradual decrease in sensitivity.

Table 1:-Electrochemical Response Characteristics Of The Investigated Electrodes

\begin{tabular}{|l|c|c|c|}
\hline Parameter & BRD-PTA & BRD-PMA & BRD-TPB \\
\hline Slope (mv/decade) & 31.89 & 29.83 & 28.50 \\
\hline Intercept (mv) & 128.15 & 94.02 & 89.50 \\
\hline LOD $\left(\mathbf{m o l}^{-1} \mathbf{~}^{-1 * *}\right.$ & $1.5 \times 10^{-7}$ & $1.8 \times 10^{-7}$ & $1.3 \times 10^{-7}$ \\
\hline Response time (s) & 25 & 25 & 25 \\
\hline Working pH range & $3-5$ & $3-5$ & $3-5$ \\
\hline Concentration range (M) & $10^{-7}-10^{-2}$ & $10^{-7}-10^{-2}$ & $10^{-7}-10^{-2}$ \\
\hline Stability (days) & 30 & 30 & 30 \\
\hline Accuracy(mean $\mathbf{\pm S . D . ) *}$ & $99.87 \pm 1.31$ & $99.77 \pm 1.55$ & $100.02 \pm 0.64$ \\
\hline Correlation coefficient $(\mathbf{r})$ & 0.9996 & 0.9994 & 0.9998 \\
\hline
\end{tabular}

* average of 5determinations. $\quad * *$ limit of detection measured by interception of the extrapolated arms.

Figure 5: Profile of the potential in $\mathrm{mV}$ versus-log concentration of BRD in $M$ obtained by using the three proposed electrodes

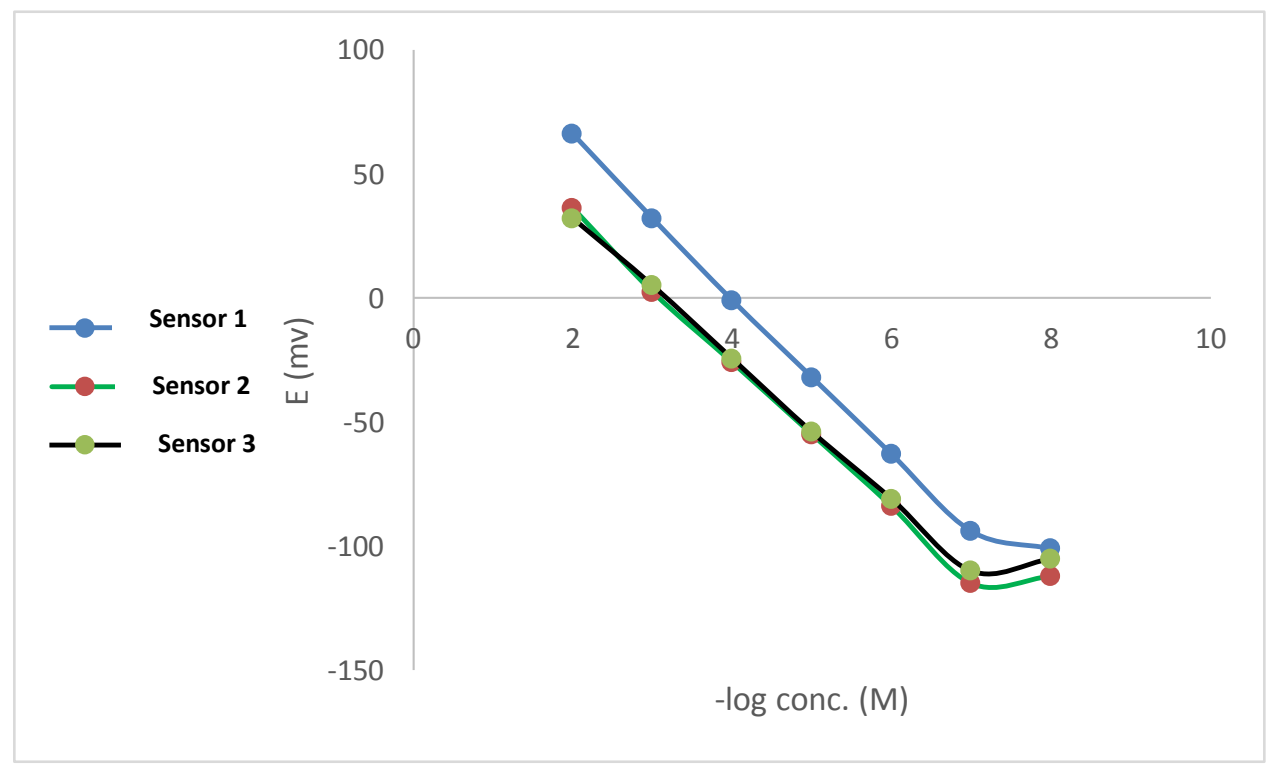

\section{Dynamic response time:}

Dynamic response time is an important factor for analytical applications of ion-selective sensors. In this study, practical response time was recorded by increasing drug concentration by up to 10 folds. The required time for the sensors to reach values within $\pm 1 \mathrm{mV}$ of the final equilibrium potential was $25 \mathrm{sec}$. For the three sensors. 


\section{Effect of pH:}

For quantitative measurements with ion selective electrodes, studies were carried out to reach the optimum experimental conditions. The potential $\mathrm{pH}$ profile, figure 6 , indicated that the responses of the sensors 1,2 and 3 were fairly constant over the $\mathrm{pH}$ range 3-5. Therefore, $\mathrm{pH} 4$ was chosen as optimum $\mathrm{pH}$ for working by the proposed sensors.

Figure 6: Effect of $\mathrm{pH}$ on the response of the three sensors at $10^{-3} \mathrm{M}$ BRD solution.

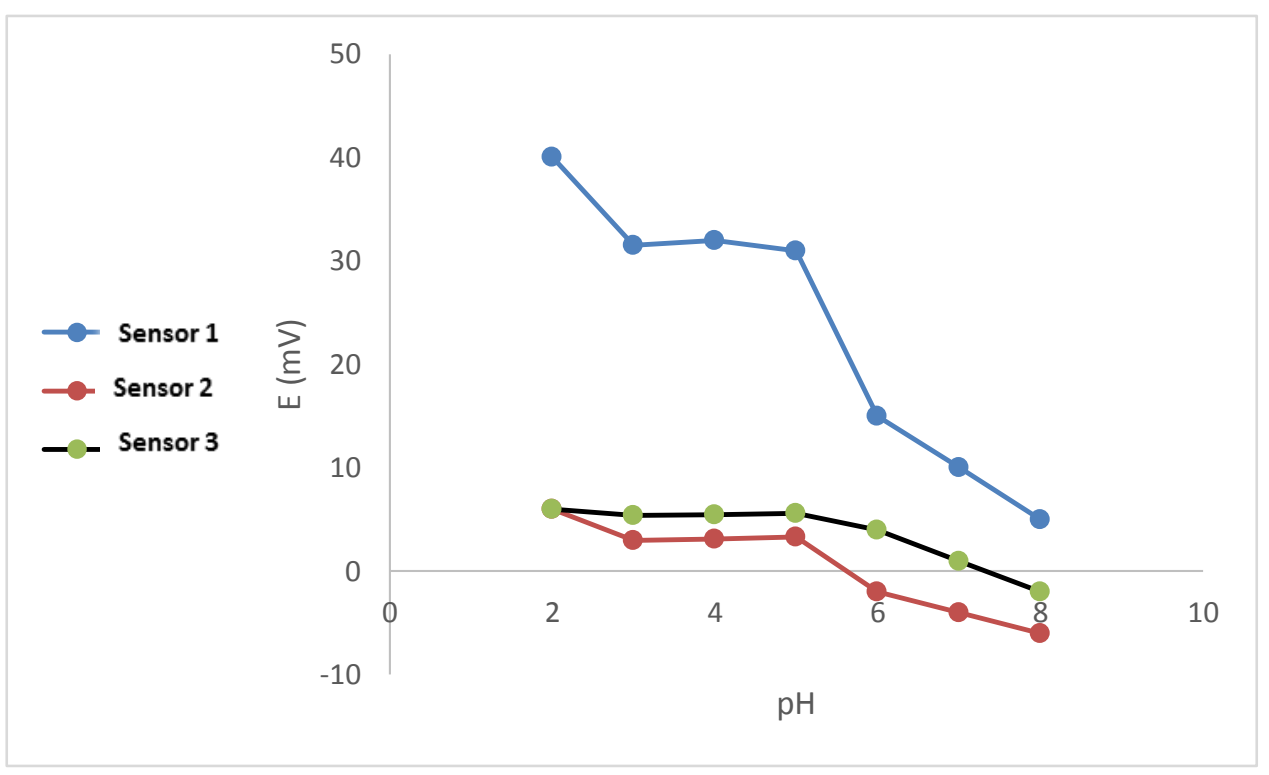

\section{Sensors selectivity:}

Table 2 shows the potentiometric selectivity coefficients of the proposed sensors in the presence of some interfering species and some inorganic cations $\left(\mathrm{K}^{+}, \mathrm{Na}^{+}\right.$and $\left.\mathrm{NH}_{4}{ }^{+}\right)$that are usually found in biological fluids. The results reveal that the proposed membrane sensors display high selectivity and that sensors 3 displays higher selectivity and lower response for the potentially interfering species than sensor 1 and 2 . The higher the selectivity coefficient value, the more the electrode membrane is attacked by the interfering cations. Thus, analysis was carried out without prior treatment or extraction.

Table2:-Potentiometric selectivity coefficients of the proposed electrodes

\begin{tabular}{|c|c|c|c|}
\hline \multirow{2}{*}{ Interferent } & \multicolumn{3}{|c|}{ Selectivity coefficient } \\
\cline { 2 - 4 } Mannitol & BRD-PTA & BRD-PMA & BRD-TPB \\
\hline Urea & $8.4 \times 10^{-4}$ & $1.1 \times 10^{-4}$ & $8.7 \times 10^{-3}$ \\
\hline $\mathbf{K C l}$ & $7.4 \times 10^{-4}$ & $3.2 \times 10^{-4}$ & $8.9 \times 10^{-3}$ \\
\hline $\mathbf{N a C l}$ & $8.8 \times 10^{-4}$ & $3.0 \times 10^{-4}$ & $1.3 \times 10^{-5}$ \\
\hline $\mathbf{C a C l}_{\mathbf{2}}$ & $9.1 \times 10^{-4}$ & $6.1 \times 10^{-4}$ & $1.1 \times 10^{-5}$ \\
\hline $\mathbf{M g C O}_{\mathbf{3} . \mathbf{6} \mathbf{H}_{2} \mathrm{O}}$ & $1.2 \times 10^{-4}$ & $1.2 \times 10^{-4}$ & $1.7 \times 10^{-5}$ \\
\hline Sucrose & $1.4 \times 10^{-4}$ & $6.1 \times 10^{-4}$ & $1.7 \times 10^{-5}$ \\
\hline Lactose & $1.5 \times 10^{-4}$ & $3.7 \times 10^{-4}$ & $1.2 \times 10^{-4}$ \\
\hline Glucose & $1.4 \times 10^{-4}$ & $3.4 \times 10^{-4}$ & $8.9 \times 10^{-4}$ \\
\hline $\mathbf{N H}_{\mathbf{4}} \mathbf{C l}$ & $1.4 \times 10^{-4}$ & $3.9 \times 10^{-4}$ & $8.7 \times 10^{-4}$ \\
\hline
\end{tabular}

Potentiometric determination in pharmaceutical formulations (Alphanova eyedrops):

The proposed sensors were applied for the analysis of BRD in Alphanova ${ }^{\circledR}$ eyedrops. The results obtained prove the applicability of the method as in table 3. Results obtained by the proposed procedure for the determination of pure samples of the drug were statistically compared to those obtained by the official B.P. method, no significant differences between the results were obtained as shown in table 4 . 
Table 3: Determination of Alpanova ${ }^{\circledR}$ eyedrops by the proposed electrodes

\begin{tabular}{|c|c|c|c|c|}
\hline \multirow{3}{*}{ Alphanova ${ }^{\circledR}$ eyedrops } & \multicolumn{3}{|c|}{ Recovery \% $\%$ S.D.* } & \multirow{2}{*}{$\begin{array}{c}\text { Reported method } \\
{[13]} \\
\end{array}$} \\
\hline & BRD-PTA & BRD-PMA & BRD-TPB & \\
\hline & $99.90 \pm 0.507$ & $99.93 \pm 0.464$ & $99.90 \pm 0.388$ & $100.15 \pm 0.378$ \\
\hline T test & 1.20 & 1.09 & 1.37 & $(\mathrm{t} \mathrm{tab}=2.11)$ \\
\hline F test & 1.78 & 1.50 & 1.05 & $(\mathrm{~F} \mathrm{tab}=4.82)$ \\
\hline
\end{tabular}

* average of 3 replicate determinations for 3 different dilutions

Table 4: Statistical comparison for the results obtained by the proposed electrodes and the official method for the analysis of BRD in pure form

\begin{tabular}{|c|c|c|c|c|}
\hline Parameter & BRD-PTA & BRD-PMA & BRD-TPB & Reported method [13] \\
\hline Mean & 99.87 & 99.77 & 100.02 & 99.82 \\
\hline SD & 1.31 & 1.55 & 0.635 & 0.752 \\
\hline N & 6 & 6 & 6 & 6 \\
\hline Variance & 1.72 & 2.40 & 0.403 & 0.565 \\
\hline t-test & 0.081 & 0.071 & $(2.23) * *$ & \\
& $(2.23) * *$ & $(2.23) * *$ & 1.40 & \\
\hline F value & 3.04 & 4.25 & $(5.05) * *$ & \\
& $(5.05) * *$ & $(5.05) * *$ & & \\
\hline
\end{tabular}

$* *$ the values in parentheses are the corresponding tabulated $\mathrm{t} \& \mathrm{f}$ values at $\mathrm{p}=0.05$

Potentiometric determination of BRD in spiked human plasma and urine:

The results obtained for the determination of BRD in spiked human plasma show that a wide concentration range of the drug can be determined by the investigated sensors with high precision and accuracy. It was found that the three sensors are reliable and give stable results with very good accuracy and high percentage recovery, which is shown in table 5. The response times of the proposed sensors are rapid (within $40 \mathrm{~s}$ ), so the sensors are rapidly transferred back and forth between the biological samples and the bi-distilled water between measurements to protect the sensing component from adhering to the surface of some matrix components. It is concluded that the proposed sensors can be successfully applied to in vitro studies and for clinical use without the need for any pretreatment or preliminary extraction procedures from biological fluids.

Table 5: Determination of BRD in spiked human plasma and spiked human urine by the proposed sensors.

\begin{tabular}{|c|l|l|l|}
\hline Results for & \multicolumn{3}{|c|}{ Recovery \% \pm S,D.* } \\
\cline { 2 - 4 } & BRD-PTA & BRD-PMA & BRD-TPB \\
\hline Spiked human plasma & $99.78 \pm 0.378$ & $100.28 \pm 0.535$ & $99.75 \pm 0.798$ \\
\hline Spiked human urine & $99.58 \pm 0.223$ & $99.86 \pm 0.335$ & $99.89 \pm 1.057$ \\
\hline
\end{tabular}

* average of 3 determinations of 3 different dilutions

\section{Conclusion:-}

The studied electrodes are sufficiently simple and selective for the quantitative determination of BRD in pure form, pharmaceutical formulation, and in biological fluids. The use of the proposed sensor offers the advantage of fast response, elimination of drug pre-treatment or separation steps, wide $\mathrm{pH}$ and concentration range and direct determination of the drug in turbid solution. They can therefore be used for the routine analysis of the drug in quality control laboratories. 


\section{References:-}

1. Bullock B L(2000) Focus on pathophysiology,Lippincott. New York, p. 1038.

2. Rang HP, Dale MM (2003) Pharmacology, 6th edition, ElSevier Science Ltd., Churchill LivingStone.

3. Brimonidine tartrate http://www.drugbank.ca/drugs/db00484.

4. Rizk MS, Merey HA, Tawakkol SM, Sweilam MN (2014) Simultaneous determination of timolol maleate and brimonidine tartarate in their pharmaceutical dosage form. Anal. Chem. Lett. 4 (2): 132-145. Doi:10.1080/22297928.2014.925825.

5. Mashru R, Senta B (2014) Development and validation of spectrophotomeric method for simutaneous estimation of brinzolamid and brimonidine tartarate. Asian j. Pharm. Life sci. 4(2) : 16-20.

6. Ibrahim F, El-Enany N, El-Shaheny RN, Mikhail IE (2014) Validated spectrofluorimetric and spectrophotometric methods for the determination of brimonidine tartrate in ophthalmic solutions via derivatization with nbd-cl . Application to stability study. Luminescence. Doi 10.1002/bio.2730. Doi:10.1002/bio.2730.

7. Bhagav P, Deshpande P, Pandey S, Chandran S (2010) Development and validation of stability indicating uv spectrophotometric method for the estimation of brimonidine tartrate in pure form, formulations and preformulation studies. Der Pharm. Lett. 2(3): 106-122.

8. Vijya P, Patel D, Desai S, Meshram D (2014) Development and validation of derivative spectrophotometric method for simultaneous estimation of brimonidine tartarate and brinzolamide in combined dosage form. Indo Am. J. Pharm. Res. 4(3) : 1472-1478.

9. Popaniya HS, Patel HM (2014) Simultaneous determination of brimonidine tartarate and timolol maleate in combined pharmaceutical dosage form using two different green spectrophotometric methods. World J. Pharm. Pharm. Sci. 3 : 1330-1340.

10. De Souza JF, Maia KN, Fialho SL, Pereira F, Da Silva GR (2014) Development and validation of spectrophotometric method for the determination of brimonidine into ocular implants. World J. Pharm. Pharm. Sci. 3(3) : 927-941.

11. Walash M, El-Shaheny R (2016) Fast separation and quantification of three anti- glaucoma drugs by highperformance liquid chromatography uv detection. J. Food Drug Anal. 1-9. Doi:10.1016/j.jfda.2015.11.006.

12. Sun J, Zhang $X$, Huang $T$ (2017) A validated stability - indicating hplc method for determination of brimonidine tartrate in bri / phema drug delivery systems. Chem. Cent. J. 11(62) : 1-10. Doi:10.1186/s13065017-0292-2.

13. Manoharan G, Al-Bratty M (2016) Development and validation of ultra violet spectrophotometric and reversedphase high performance liquid chromatography techniques for simultaneous estimation of brinzolamide and brimonidine tartrate in ophthalmic suspension formulation. Orient. J. Chem. 32(2) : 1111-1120.

14. Madhavi A, Naidu A, Rao DVS, Srinivasu P (2009) Development and validation of a new lc method for analysis of brimonidine tartrate and related compounds. Chromatographia 10 (13) doi:10.1365/s10337-0091083-2.

15. Mehta SK, Maheshwari DG (2014) Analytical method development and validation for simultaneous estimation of timolol maleate and brimonidine tartrate in bulk and marketed ophthalmic formulation. J. Pharm. Sci. Biosientific Res. 4 (6): 351-356.

16. Hassib ST, Elkady EF, Sayed RM (2016) Simultaneous determination of timolol maleate in combination with some other anti-glaucoma drugs in rabbit aqueous humor by high performance liquid chromatography-tandem mass spectroscopy. J. Chromatogr. B. Doi:10.1016/j.jchromb.2016.04.012.

17. Rizk MS, Merey HA, Tawakkol SM, Sweilam MN (2015) development and validation of a stability-indicating micellar liquid chromatographic method for the determination of timolol maleate in the presence of its degradation products. J. Chromatogr. Sci. 5(3) : 503-510.

18. Elshanawane AA, Abdelaziz LM, Mohram MS, Hafez HM (2014) Development and validation of hplc method for simultaneous estimation of brimonidine tartrate and timolol maleate in bulk and pharmaceutical dosage form. J. Chromatogr. Sep. Tech. 5(3) : 1-5. Doi:10.4172/2157-7064.1000230.

19. Anand M, Fonseca A, Ghandi SV, Padmanabh DB (2010) Development and validation of high performance thin layer chromatographic method for estimation of brimonidine tartrate as bulk drug and in ophthalmic solutions. Int. J. Pharmtech res. 2(3) : 1376-1379.

20. Sonanis MC, Rajput AP (2011) Development and vaidation of a new stability indicating analytical method for the determination of related components of brimonidine tartarate in drug substances and drug product using uplc. Int. J. Pharm. Pharm. Sci. 3 (1) : 145-150.

21. Büker E, Dinç E (2016) A new uplc method with chemometric design - optimization approach for the simultaneous quantitation of brimonidine tartrate and timolol maleate in an eye drop preparation. J. 
Chromatogr. Sci. 1-8. Doi:10.1093/chromsci/bmw160.

22. Radulovic V, Aleksic MM, Agbaba D, Kapetanovic V (2012) An electroanalytical approach to brimonidine at boron doped diamond electrode based on its extensive voltammetric study. Electroanalysis. 25 (1): $230-236$. Doi:10.1002/elan.201200400.

23. Aleksi MM, Radulovi V, Agbaba D, Kapetanovi V (2013) An extensive study of electrochemical behavior of brimonidine and its determination at glassy carbon electrode. Electrochim. Acta. 106 (1) :75-81. Doi:10.1016/j.electacta.2013.05.053.

24. Radulovi V, Agbaba D, Kapetanovi V, Aleksi MM (2013) An extensive study of electrochemical behavior of brimonidine and its determination at glassy carbon electrode, Electrochimica Acta 106 (1): 75-81. Doi:10.1016/j.electacta.2013.05.053.

25. IUPAC (2000) Analytical chemistry division, Commission on analytical nomenclature. Pure Appl Chem. 72 : 1851. 